\title{
The Impact of Anthropogenic Climate Change on North Atlantic Tropical Cyclone Tracks*
}

\author{
Angela J. Colbert And Brian J. SOdEN \\ Rosenstiel School of Marine and Atmospheric Science, University of Miami, Miami, Florida \\ GABRIEL A. VECCHI \\ NOAA/Geophysical Fluid Dynamics Laboratory, Princeton, New Jersey \\ BEN P. KIRTMAN \\ Rosenstiel School of Marine and Atmospheric Science, University of Miami, Miami, Florida
}

(Manuscript received 6 June 2012, in final form 10 December 2012)

\begin{abstract}
The authors examine the change in tropical cyclone (TC) tracks that results from projected changes in the large-scale steering flow and genesis location from increasing greenhouse gases. Tracks are first simulated using a Beta and Advection Model (BAM) and NCEP-NCAR reanalysis winds for all TCs that formed in the North Atlantic Ocean's Main Development Region (MDR) for the period 1950-2010. Changes in genesis location and large-scale steering flow are then estimated from an ensemble mean of 17 models from phase 3 of the Coupled Model Intercomparison Project (CMIP3) for the A1b emissions scenario. The BAM simulations are then repeated with these changes to estimate how the TC tracks would respond to increased greenhouse gases. As the climate warms, the models project a weakening of the subtropical easterlies as well as an eastward shift in genesis location. This results in a statistically significant decrease in straight-moving (westward) storm tracks of $\sim 5.5 \%$ and an increase in recurving (open ocean) tracks of $\sim 5.5 \%$. These track

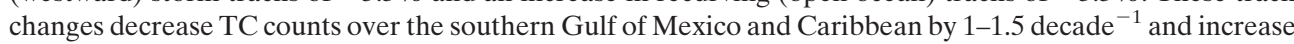
counts over the central Atlantic by $1-1.5 \mathrm{decade}^{-1}$. Changes in the large-scale steering flow account for a vast majority of the projected changes in TC trajectories.
\end{abstract}

\section{Introduction}

The impact of rising $\mathrm{CO}_{2}$ on tropical cyclones (TCs) is an area of great interest. Previous studies have focused on the effects of anthropogenic climate change on TC frequency and intensity (Landsea et al. 2006; Bengtsson et al. 2007; Elsner et al. 2008; Gualdi et al. 2008; Knutson et al. 2008; Garner et al. 2009; Knutson et al. 2010; Yu et al. 2010; Zhao and Held 2010). For example, a recent assessment projects a reduction of global TC frequency

\footnotetext{
* Supplemental information related to this paper is available at the Journals Online website: http://dx.doi.org/10.1175/ JCLI-D-12-00342.s1.

Corresponding author address: Angela J. Colbert, Rosenstiel School of Marine and Atmospheric Science, University of Miami, 4600 Rickenbacker Causeway, Miami, FL 33149.

E-mail: acolbert@rsmas.miami.edu
}

of $6 \%-34 \%$ and an increase in intensity of $2 \%-11 \%$ by the end of the twenty-first century (Knutson et al. 2010).

The potential impact of anthropogenic climate change on TC tracks has received less attention. Vecchi and Soden (2007) noted an eastward shift in climate model simulations of the Genesis Potential Index (GPI; Emanuel and Nolan 2004) over the North Atlantic Ocean's Main Development Region (MDR) in response to increased $\mathrm{CO}_{2}$. This eastward shift in genesis location was identified as a potential cause for the decrease in U.S. landfalling TCs over the Southeast and increase over the Northeast in high-resolution model simulations by Murakami and Wang (2010, hereafter MW10). Moreover, when the impact of evolving observing networks on historical record is taken into consideration, an eastward shift in the location of North Atlantic TC tracks since the late nineteenth century appears in the observed record (Vecchi and Knutson 2008, 
2011), qualitatively similar to the projections for an eastward shift. In addition, Wu and Wang (2004) used a high-resolution GCM to suggest changes in TC tracks caused by rising $\mathrm{CO}_{2}$ could result from shifts in both the large-scale steering flow and genesis location.

We use a Beta and Advection Model (BAM) in conjunction with reanalysis wind fields and climate model simulations to examine the impact of changes in the large-scale steering flow and genesis location on TC tracks. This approach permits us to consider potential changes in steering flow and genesis location from a large multimodel ensemble mean rather than just an individual model. It also allows us to isolate the impact of changes in the large-scale steering flow from that caused by changes in genesis location, thus providing insight into their relative importance. Based upon these projections, we find a statistically significant decrease in straight-moving (westward) storm tracks and an increase in recurving (open ocean) tracks. This shift is shown to primarily result from changes in the large-scale steering flow rather than from changes in genesis location.

\section{Methodology}

The BAM uses a deep-layer steering flow that is computed from the horizontal wind fields $\mathbf{V}$ at 850, 500, and $200 \mathrm{mb}$ defined as $\mathbf{V}=0.25 \mathbf{V}_{850 \mathrm{mb}}+0.5 \mathbf{V}_{500 \mathrm{mb}}+$ $0.25 \mathbf{V}_{200 \mathrm{mb}}$; and an empirically determined $\beta$ drift [see Colbert and Soden (2012, hereafter CS12) for details]. The Atlantic basin hurricane database (HURDAT; Jarvinen et al. 1984; McAdie et al. 2009) is used to obtain the locations of the $256 \mathrm{TCs}$ that formed in the MDRdefined as the area south of $20^{\circ} \mathrm{N}$ and west of $65^{\circ} \mathrm{W}-$ between 1950 and 2010 (CS12). Following CS12, control simulations (CTRL) are performed by initializing each $\mathrm{TC}$ at its historical genesis location and, using the BAM model, advected for the lifetime of that TC using the corresponding steering flow obtained from the National Centers for Environmental Prediction-National Center for Atmospheric Research (NCEP-NCAR) reanalysis (Kalnay et al. 1996). For the A1b radiative forcing scenario simulation (atmospheric $\mathrm{CO}_{2}$ stabilization at $720 \mathrm{ppm}$ by 2100), the model-projected changes in steering flow and genesis location are accounted for as described below.

To examine the impact of increasing greenhouse gases on the TC steering flow, monthly zonal $u$ and meridional $v$ wind anomalies for 850,500 , and $200 \mathrm{mb}$ are computed for each of 17 models from phase 3 of the Coupled Model Intercomparison Project (CMIP3; see Table S1 in the supplemental materials). The anomalies are calculated as the difference between the 20 -yr averages (where square brackets indicate an average) at the end and beginning of the twenty-first century ([2081-2100] [2001-20]). The monthly anomalies for each model are added to the corresponding NCEP-NCAR reanalysis winds, where they are linearly interpolated in time to match the 6-hourly reanalysis fields. The BAM model is then run for all 256 TCs as in the CTRL simulation, but with the modified wind fields for each of the CMIP3 models. The resultant TC tracks, as well as the wind anomalies used to obtain the tracks, are averaged to obtain a multimodel ensemble mean.

To examine the influence of changes in genesis location on TC tracks, we use the GPI calculations for the same 17 CMIP3 models from Vecchi and Soden (2007), which are based on the formulation of Emanuel and Nolan (2004). The seasonal (June-November) average GPI is calculated for the first $20 \mathrm{yr}$ (2001-20; CTRL) and last $20 \mathrm{yr}$ (2081-2100; A1b) of the A1b scenario. The difference in GPI ([2081-2100] - [2001-20]) is computed for each model and then averaged to form the ensemble mean change. For both the CTRL and A1b simulations, the storm count in each grid box of a given TC is weighted by the GPI of the genesis location for that storm. Although each model has its own biases, the simulated GPI at the beginning and end of the twentyfirst century is well sampled using observed genesis locations because the GPI and observed genesis distribution patterns have similar spatial distributions. Thus, we assume that there is not a significant contribution from areas where TC genesis did not historically occur. While changes in TC intensity may indirectly be accounted for through the use of the GPI, the BAM simulations performed for this study use the same deep-layer steering levels for all storms. Although a relationship between storm intensity and steering level has been observed (Dong and Neumann 1986; Velden 1993), no attempt is made to account for such behavior in this study.

\section{Results}

Figures $1 \mathrm{a}$ and $1 \mathrm{~b}$ compare the regional distribution of observed and BAM-simulated TC counts for the period 1950-2010. While the BAM captures the overall distribution of storm density, the simulated tracks tend to have a larger spread relative to the observations resulting in smaller maxima in the tropical and midlatitude central Atlantic. While an accurate representation of the climatological distribution of TC tracks is one test of the model, for the purposes of this study it is more important that the model capture changes in TC tracks caused by a change in genesis location or steering flow. To evaluate this, CS12 examined the model's ability to simulate the response of TC tracks to naturally driven 

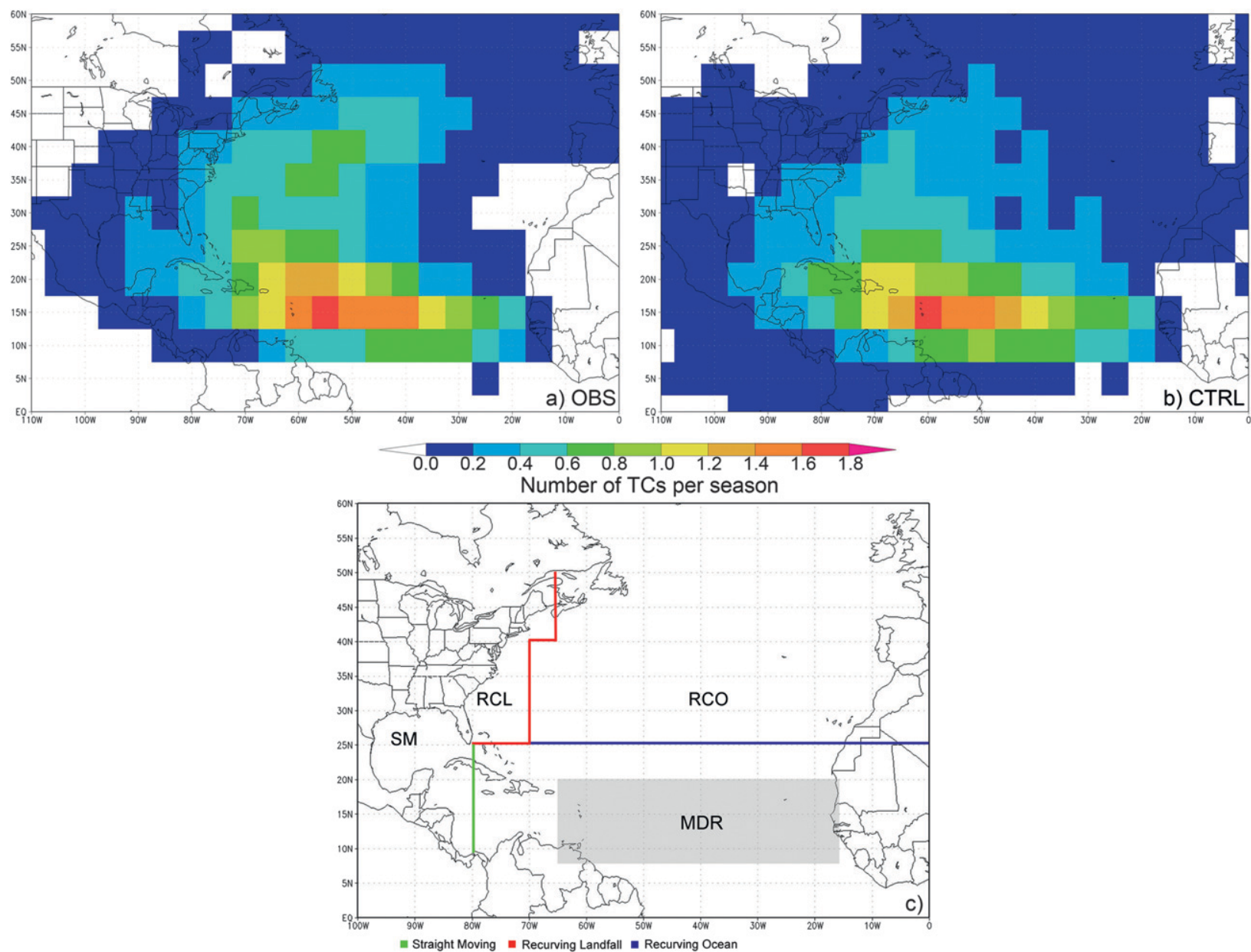

FIG. 1. The mean track distribution over 61 seasons for all MDR forming TCs from 1950 to 2010 in (a) observations (OBS) and (b) BAM-simulated tracks with corresponding NCEP-NCAR reanalysis wind fields (CTRL). All grid boxes are $5^{\circ} \times 5^{\circ}$. (c) From CS12, the track boundaries for classifying TC tracks. The SM TCs (green) threaten the Caribbean and Gulf Coast. The RCL TCs (red) threaten the U.S. East Coast. The RCO TCs (blue) never threaten the United States. All TCs had to form in the MDR (gray).

variations in climate. They showed that the model successfully reproduced the observed shift in tracks associated with El Niño-Southern Oscillation (ENSO) and the Atlantic Meridional Mode (AMM), and the absence of any significant change in tracks associated with the North Atlantic Oscillation (NAO). This lends credibility to the model's ability to simulate changes in TC tracks from anthropogenic climate change.

Following CS12, the tracks are classified into three categories: straight moving (SM), recurving landfall (RCL), and recurving ocean (RCO) as defined in Fig. 1c (see also CS12). The SM TCs threaten the Caribbean and Gulf Coast, RCL TCs threaten the U.S. East Coast, and RCO TCs recurve into the ocean without threatening the United States. The TCs that dissipate before reaching one of the defined boundaries are also included as described in CS12.
The CMIP3 projected changes in both genesis location and the large-scale steering flow lead to modest, but statistically significant, shifts in tracks. For the CTRL and $\mathrm{A} 1 \mathrm{~b}$ simulations, the tracks are reclassified into $\mathrm{SM}$, RCL, and RCO TC tracks. The warming climate is associated with a statistically significant reduction of SM TCs $(5.5 \%)$ and a statistically significant increase of RCO TCs (5.5\%; Fig. 2c). Using a two-tailed binomial test (see CS12), the changes in SM and RCO are determined to be significant at the $91 \%$ and $92 \%$ level, respectively. The changes are also robust with 15 of the 17 models projecting a decrease in SM TCs and 12 of the 17 models projecting an increase in RCO TCs. However, no changes in RCL TC track frequency are found.

To investigate the spatial distribution of the shift in track frequency, the distribution of storm counts for both the CTRL and A1b simulations are plotted in 

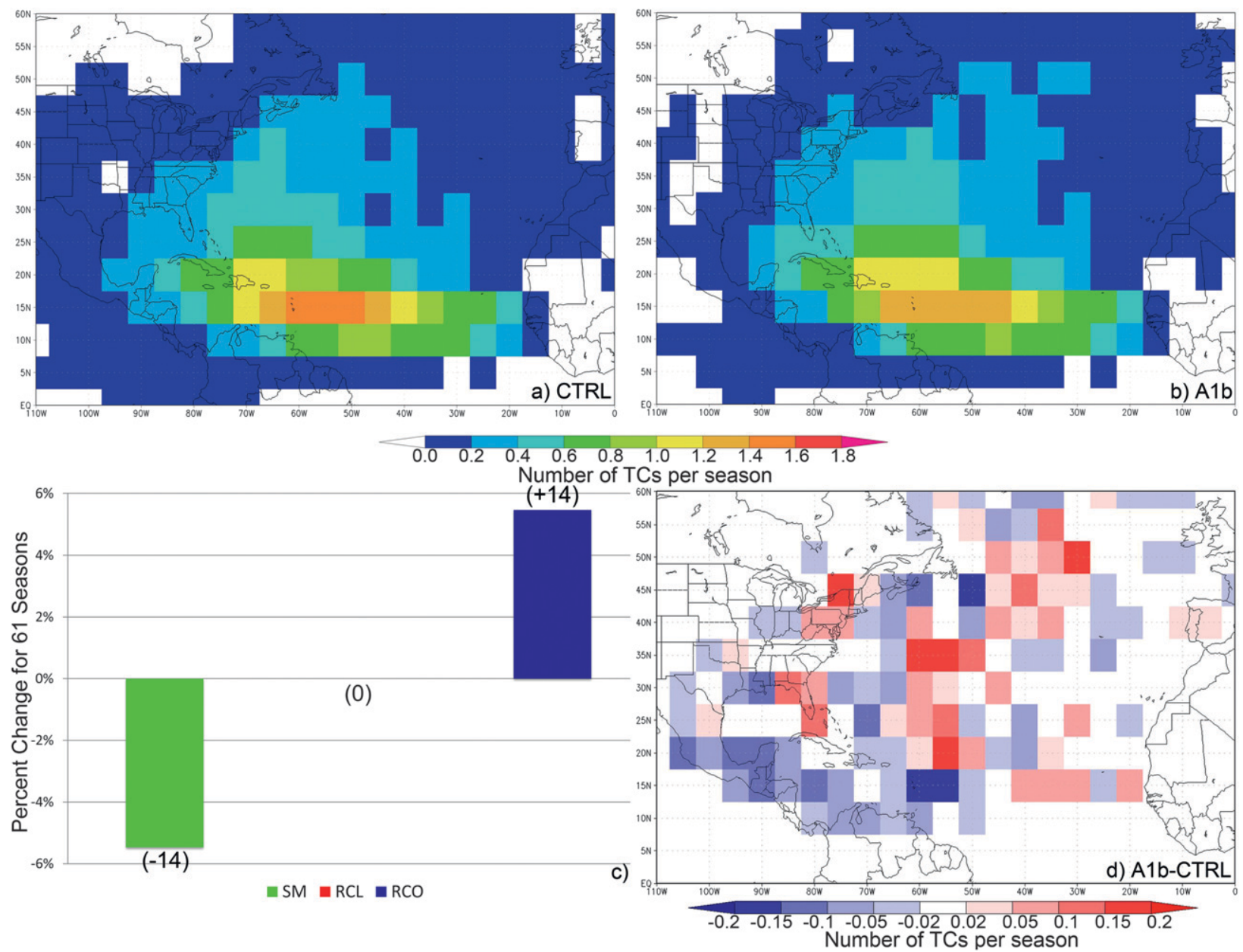

FIG. 2. The mean track distribution over 61 seasons for all MDR forming TCs in (a) BAM-simulated tracks (CTRL) weighted by the 20-yr, 17-model ensemble mean GPI at the beginning of the twenty-first century (2001-20, CTRL GPI) and (b) BAM-simulated tracks with the 17-model ensemble mean anomalous winds from each respective model added to the historical wind fields (A1b) weighted by the 20-yr, 17-model ensemble mean GPI at the end of the twenty-first century (2081-2100, A1b GPI). (c) The percent change in track frequency between the CTRL and A1b simulations for SM, RCL, and RCO TCs (A1b - CTRL). The number in parentheses is the number of TCs that changed over 61 seasons for each respective track classification. (d) The track density difference of A1b - CTRL. The contour levels are $0.2,0.15,0.1,0.05$, and 0.02 where blue is negative and red is positive, and 0.1 is equivalent to $1 \mathrm{TC}^{\mathrm{decade}}{ }^{-1}$. All grid boxes are $5^{\circ} \times 5^{\circ}$.

Figs. $2 \mathrm{a}$ and $2 \mathrm{~b}$, respectively. The difference in storm counts between the CTRL and A1b simulation (A1b CTRL; Fig. 2d) shows substantial regional variability. There is a spatially coherent reduction in TCs by $1-1.5$ decade $^{-1}$ over the southern Gulf of Mexico, Caribbean, and Central America, which is primarily responsible for the reduction in SM TCs. Conversely, there is an increase in storm counts throughout the mid-Atlantic of approximately $1-1.5 \mathrm{TCs} \mathrm{decade}^{-1}$, which is responsible for the increase in RCO TCs. Although there is no change in RCL track frequency, the distribution suggests a slight increase along the U.S. Southeast and Northeast coasts and decrease in the ocean adjacent to the coastline. This finding suggests recurvature occurs more frequently such that a portion of SM TCs become RCL TCs, and a portion of RCL TCs become RCO TCs.

To interpret the causes of these shifts in tracks, we examine the changes in the GPI and large-scale steering flow. As noted in Vecchi and Soden (2007), the 17-model ensemble mean difference ([2081-2100] - [2001-20]) shows an eastward shift in genesis location in the MDR (Fig. 3a). Although a majority of the models (12 out of 17) agree on an increase in GPI over the eastern MDR, the magnitude of this shift varies substantially from model to model.

Figure $3 \mathrm{~b}$ depicts the composite of the deep-layer steering flow used in the BAM simulations for all 256 storms for the NCEP-NCAR reanalysis wind fields. 

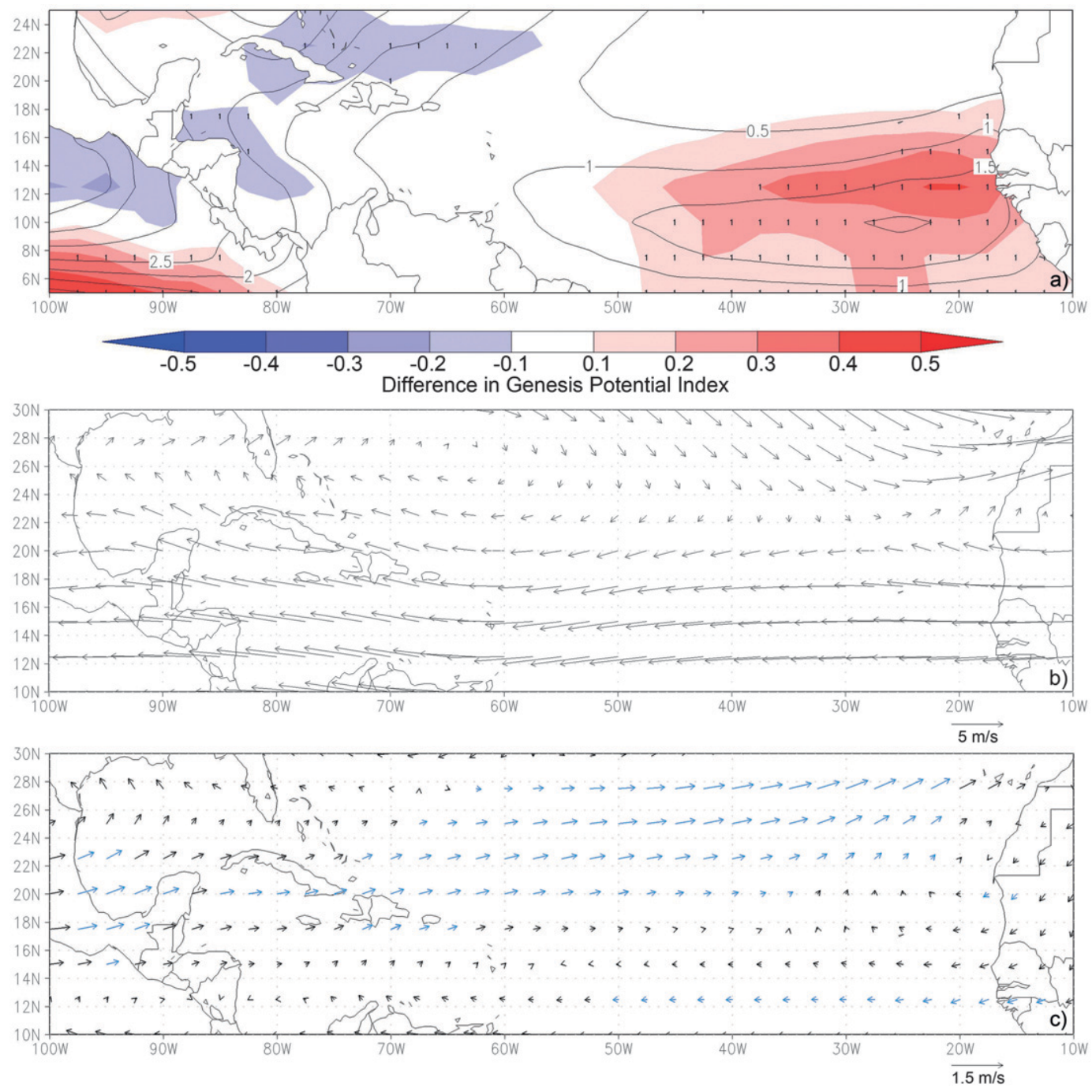

FIG. 3. (a) The 17-model ensemble mean difference ([2081-2100] - [2001-20]) in GPI. The shaded contour levels are $0.1,0.2,0.3,0.4$, and 0.5 where blue is negative and red is positive. The black contours are the 17-model ensemble mean control (2001-20) GPI. Vertical dashes are where 12 or more of the 17 models agree on the sign of change. (b) The black arrows are the corresponding NCEP-NCAR reanalysis deep-layer steering flow averaged over all MDR forming TCs for their duration from 1950 to 2010 (scale provided below panel). (c) The anomalous deep-layer steering flow difference ([2081-2100] - [2001-20]) averaged over all MDR forming TCs for their duration (black/ blue arrows; scale provided below panel). The blue arrows are where 12 or more of the 17 models agree on the zonal sign of change.

Figure $3 \mathrm{c}$ shows a similar composite of the A1b wind anomalies ([2081-2100] - [2001-20]) for the 17-model ensemble mean (black arrows), where the blue arrows indicate anomalies in which 12 or more of the 17 models agree on the sign of the change in zonal wind. The most prominent feature is the westerly wind anomaly across the southern Gulf of Mexico and Caribbean that extends into the Atlantic. This wind anomaly weakens the easterlies and encourages recurvature of TCs away from the Caribbean and southern Gulf of Mexico, which is consistent with the projected increase in RCO tracks and the decrease in SM tracks.
To determine whether changes in genesis location or large-scale steering flow are the primary cause of the projected changes in TC tracks, we use the BAM to isolate their individual contributions.

\section{a. Genesis}

To isolate the impact of changes in genesis location, we compare the results obtained by weighting the tracks simulated from the NCEP winds (Fig. 1b) by the CTRL and A1b GPI. Differences between the CTRL and A1b GPI climate result in very small and statistically insignificant changes (at the $90 \%$ level) in the frequency of 

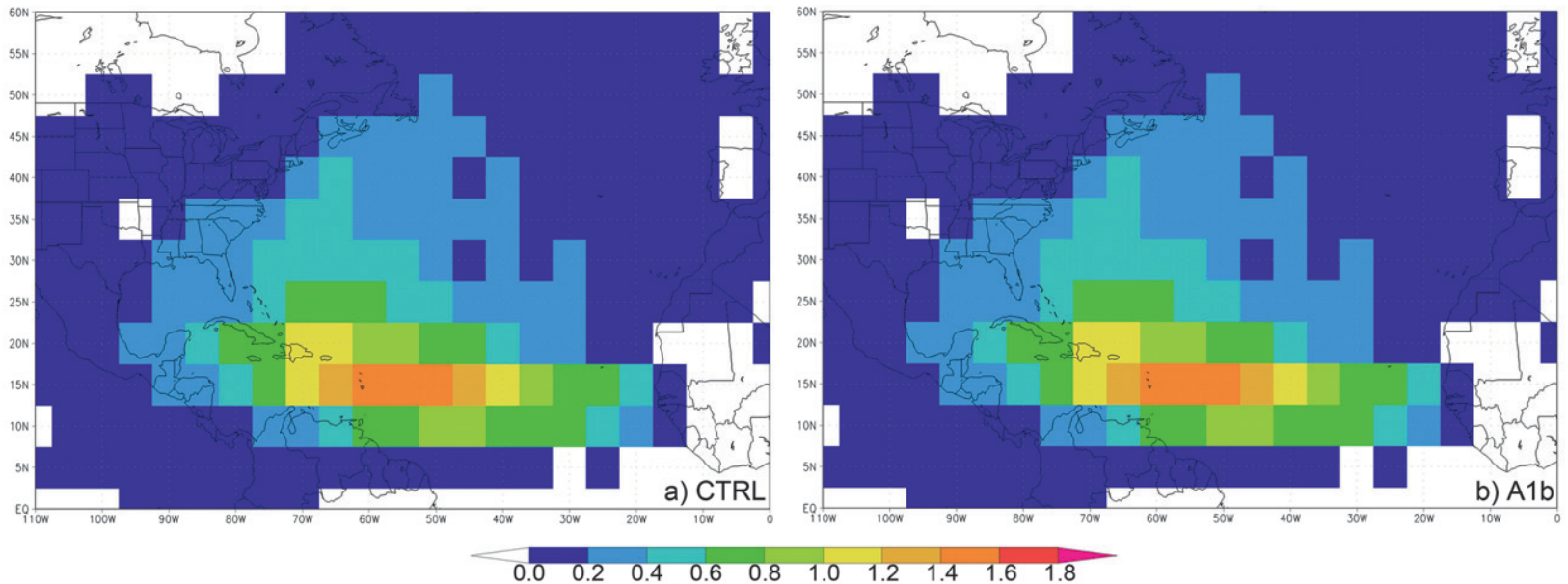

Number of TCs per season

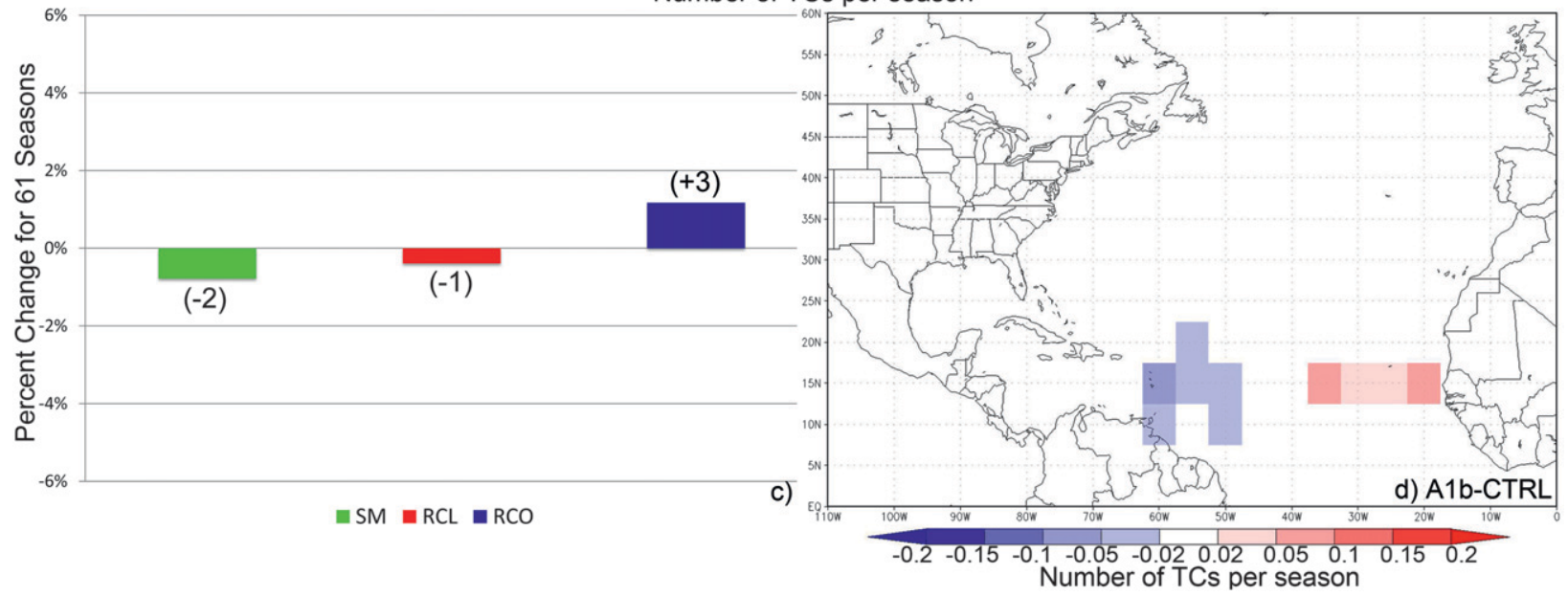

FIG. 4. As in Fig. 2, but the changes in genesis location are isolated to show the NCEP wind tracks that are weighted by the (a) CTRL GPI and (b) A1b GPI and the resulting differences.

track types. There is a slight increase in RCO TCs and decrease in SM and RCL TCs in 12 of the 17 models, consistent with an eastward shift in GPI. However, the ensemble-mean changes are small relative to the simulations that consider both GPI and large-scale steering flow (Fig. 4c).

Figures $4 \mathrm{a}$ and $4 \mathrm{~b}$ illustrate the track distributions for the CTRL and A1b GPI simulations, respectively. The projected distribution for the A1b GPI simulation is very similar to the distribution for the CTRL GPI simulation. The differences between the CTRL and A1b GPI-weighted NCEP tracks are very small with a slight enhancement in the eastern MDR and a slight reduction in the western MDR (A1b - CTRL; Fig. 4d). This is consistent with the projected changes in the frequency of track types, but they are not statistically significant.

\section{b. Large-scale steering flow}

To isolate the impact of changes in the large-scale steering flow, the CTRL TC count is compared with the
A1b TC count (as in Fig. 2), but excluding the respective GPI weighting for both simulations (Figs. 5a,b). Changes between the two simulations result in an increase in RCO $(4.7 \%)$ and a decrease in SM $(3.9 \%)$ and RCL $(0.8 \%)$ TCs by the end of the twenty-first century (Fig. $5 c$ ). The increase in RCO and decrease in SM TCs are not significant at the $90 \%$ level. Both of the changes are robust with 15 out of 17 models projecting a decrease in SM and 14 out of 17 models projecting an increase in RCO TCs when the changes in the large-scale steering flow are isolated. These shifts are consistent with a weakening of the subtropical easterlies, which allows for more TCs to recurve.

The difference between the CTRL and A1b simulation is shown in Fig. 5d. There is an increase in tracks over the central North Atlantic of approximately 1-1.5 TCs decade ${ }^{-1}$ and a decrease in tracks of approximately 1-1.5 TCs decade ${ }^{-1}$ over the Caribbean, southern Gulf of Mexico, and Central America. As with the GPI, the spatial changes correspond to the projected increase in RCO and decrease in SM TC track frequency. 

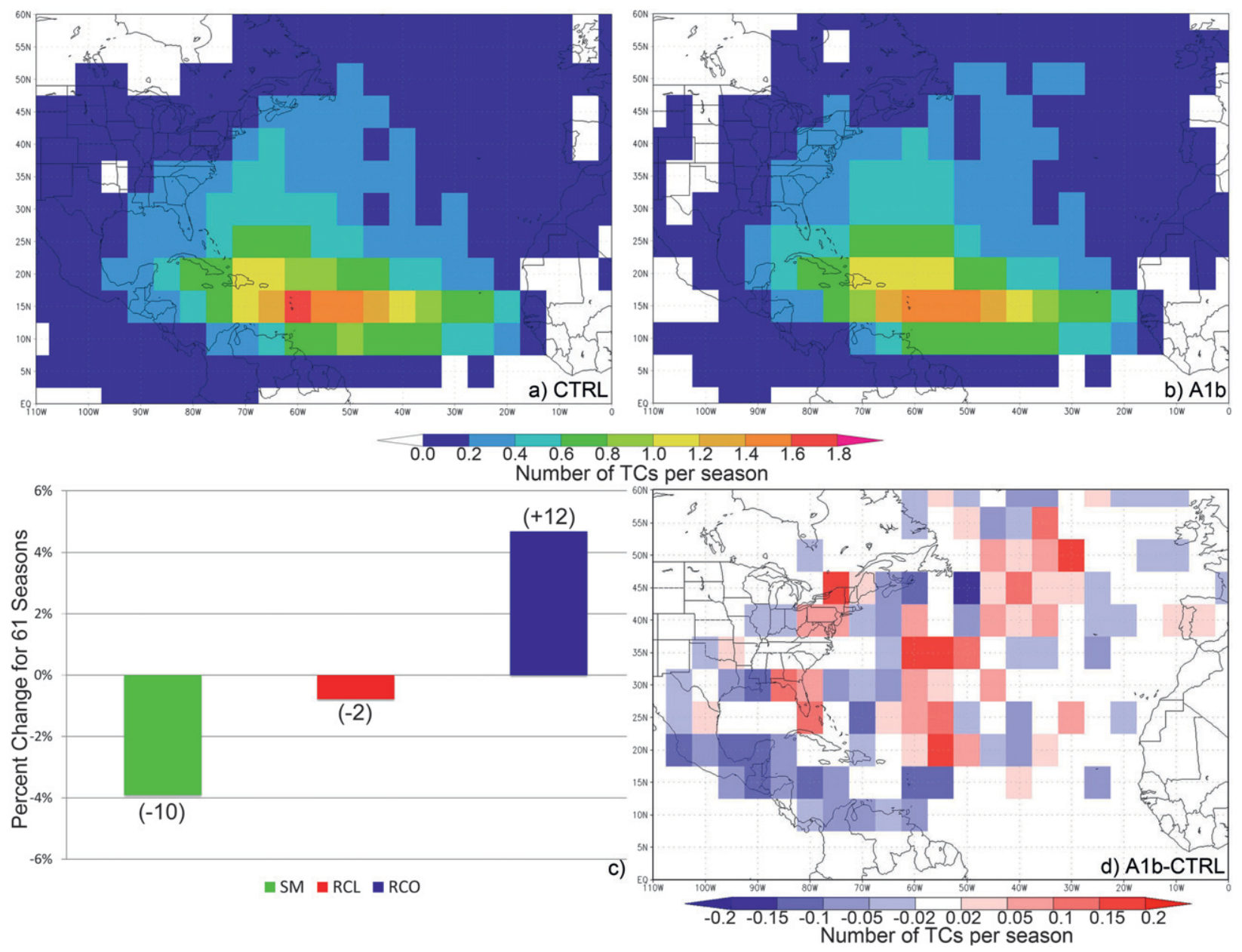

FIG. 5. As in Fig. 2, but the changes in the large-scale steering flow are isolated to show the (a) CTRL (NCEP winds) and (b) A1b (NCEP and anomalous winds) tracks and the resulting differences.

This analysis suggests that changes in the large-scale steering flow are the primary contributor to the projected shifts in TC track frequency and distribution. However, the decrease in SM and increase in RCO TCs are smaller when only the large-scale steering flow is considered than when both the large-scale steering flow and GPI for the end of the twenty-first century are combined. This suggests that while the eastward shift in genesis location in the MDR is small, it complements the changes in large-scale steering flow and contributes to the overall projected changes in TC tracks.

\section{Summary and discussion}

We examined the impact of projected increases in $\mathrm{CO}_{2}$ on North Atlantic TC tracks. Simulated changes in the large-scale steering flow and genesis location suggest a statistically significant decrease of $5.5 \%$ of SM and an increase of $5.5 \%$ of RCO TCs. These shifts in track frequency result in a reduction of storm counts over the southern Gulf of Mexico, Caribbean, and Central America of approximately 1-1.5 TCs decade ${ }^{-1}$ and an increase in storm counts across the mid-Atlantic of approximately $1-1.5 \mathrm{TCs}^{\mathrm{T}} \mathrm{Tecade}^{-1}$. Changes in the largescale steering flow, which result from a weakening of the subtropical easterlies, steer TCs away from the Gulf and Caribbean region contributing to a decrease in SM TCs. However, the decrease in SM TCs is not statistically significant without also accounting for the eastward shift of genesis location in the MDR. This result suggests that changes in both the large-scale steering flow and genesis location are important factors for TC tracks in the North Atlantic, with the steering flow being the primary contributor.

These results agree with MW10, in that both studies find a tendency for an eastward shift of North Atlantic tropical storm tracks. However, the dominant mechanism here differs from that of MW10, who suggested that the primary contributor to a shift in tracks was an eastward shift in genesis location. MW10 found a 
decrease in TCs over the Caribbean, Gulf of Mexico, and U.S. Southeast and an increase in recurving tracks, including an increase over the U.S. Northeast. The results of this study support an increase in recurving and decrease in straight-moving TCs, but statistically significant changes for the eastern United States are not found. However, a slight increase in the track distribution along the U.S. Northeast coast and decrease offshore suggests that a portion of SM become RCL TCs, and a portion of RCL become RCO TCs. Differences in the methodology of the two studies may create this discrepancy in the results. MW10 used one high-resolution model to simulate changes in TC frequency, genesis, and track, which may have limited TC simulation abilities in the MDR. We use a 17-model ensemble mean and decompose the results into changes in tracks caused by genesis location and changes in large-scale steering flow, but assume no change in TC frequency. In addition, we use the historical genesis distribution to initialize the BAM, whereas MW10 used model-estimated genesis.

This study focused on the tropical North Atlantic only, where the observational record is the most reliable and where the BAM has proven to be an effective tool for studying change in TC tracks associated with natural variations in climate. We note that the more substantial changes in large-scale steering flow and genesis location may occur in other ocean basins (e.g., the western North Pacific) and a similar analysis is planned for future work that includes an analysis with models from phase 5 of the Coupled Model Intercomparison Project (CMIP5).

Acknowledgments. This research was partially supported by the NOAA/Climate Program Office. We thank Chris Landsea, Amy Clement, and three anonymous reviewers for their comments.

\section{REFERENCES}

Bengtsson, L., K. I. Hodges, M. Esch, N. Keenlyside, L. Kornbluegh, J. Luo, and T. Yamagata, 2007: How may tropical cyclones change in a warmer climate? Tellus, 59A, 539-561, doi:10.1111/ j.1600-0870.2007.00251.x.

Colbert, A. J., and B. J. Soden, 2012: Climatological variations in North Atlantic tropical cyclone tracks. J. Climate, 25, 657-673.

Dong, K., and C. J. Neumann, 1986: The relationship between tropical cyclone motion and environmental geostrophic flows. Mon. Wea. Rev., 114, 115-122.

Elsner, J. B., J. P. Kossin, and T. H. Jagger, 2008: The increasing intensity of the strongest tropical cyclones. Nature, 455, 92-95, doi:10.1038/nature07234.
Emanuel, K. A., and D. S. Nolan, 2004: Tropical cyclone activity and the global climate system. Preprints, 26th Conf. on Hurricanes and Tropical Meteorology, Miami, FL, Amer. Meteor. Soc., 10A.2. [Available online at https://ams.confex.com/ams/ 26HURR/techprogram/paper_75463.htm.]

Garner, S. T., I. M. Held, T. Knutson, and J. Sirutis, 2009: The roles of wind shear and thermal stratification in past and projected changes of Atlantic tropical cyclone activity. J. Climate, 22, 4723-4734.

Gualdi, S., E. Scoccimarro, and A. Navarra, 2008: Changes in tropical cyclone activity due to global warming: Results from a high-resolution coupled general circulation model. J. Climate, 21, 5204-5228.

Jarvinen, B. R., C. J. Neumann, and M. A. S. Davis, 1984: A tropical cyclone data tape for the North Atlantic basin, 18861983. NOAA Tech. Memo. NWS/NHC 22, 21 pp.

Kalnay, E., and Coauthors, 1996: The NCEP/NCAR 40-Year Reanalysis Project. Bull. Amer. Meteor. Soc., 77, 437-471.

Knutson, T. R., J. J. Sirutis, S. T. Garner, G. A. Vecchi, and I. M. Held, 2008: Simulated reduction in Atlantic hurricane frequency under twenty-first-century warming conditions. Nat. Geosci., 1, 359-364, doi:10.1038/ngeo202.

- , and Coauthors, 2010: Tropical cyclones and climate change. Nat. Geosci., 3, 157-163, doi:10.1038/ngeo779.

Landsea, C. W., B. A. Harper, K. Hoarau, and J. A. Knaff, 2006: Can we detect trends in extreme tropical cyclones? Science, 313, 452-454, doi:10.1126/science.1128448.

McAdie, C. J., C. W. Landsea, C. J. Neuman, J. E. David, E. Blake, and G. R. Hamner, 2009: Tropical cyclones of the North Atlantic Ocean, 1851-2006. Historical Climatology Series 6-2, National Climatic Data Center, Asheville, NC, and National Hurricane Center, Miami, FL, 238 pp.

Murakami, H., and B. Wang, 2010: Future change of North Atlantic tropical cyclone tracks: Projection by a $20-\mathrm{km}-\mathrm{mesh}$ global atmospheric model. J. Climate, 23, 2699-2721.

Vecchi, G. A., and B. J. Soden, 2007: Increased tropical Atlantic wind shear in model projections of global warming. Geophys. Res. Lett., 34, L08702, doi:10.1029/2006GL028905.

—_, and T. R. Knutson, 2008: On estimates of historical North Atlantic tropical cyclone activity. J. Climate, 21, 3580-3600.

- , and - 2011: Estimating annual numbers of Atlantic hurricanes missing from the HURDAT database (1878-1965) using ship track density. J. Climate, 24, 1736-1746.

Velden, C., 1993: The relationship between tropical cyclone motion, intensity, and the vertical extent of the environmental steering layer in the Atlantic basin. Preprints, 20th Conf. on Hurricanes and Tropical Meteorology, San Antonio, TX, Amer. Meteor. Soc., 31-34.

Wu, L., and B. Wang, 2004: Assessing impacts of global warming on tropical cyclone tracks. J. Climate, 17, 1686-1698.

Yu, J., Y. Wang, and K. Hamilton, 2010: Response of tropical cyclone potential intensity to a global warming scenario in the IPCC AR4 CGCMs. J. Climate, 23, 1354-1373.

Zhao, M., and I. M. Held, 2010: An analysis of the effect of global warming on the intensity of Atlantic hurricanes using a GCM with statistical refinement. J. Climate, 23, 63826393. 